\title{
Importance of Silicon Atom in the Drug Design Process
}

\author{
Changdev G. Gadhe ${ }^{1 \dagger}$ and Seung Joo $\mathrm{Cho}^{2,3 \dagger}$
}

\begin{abstract}
The pharmaceutical industry has an ongoing need for new, safe medicines with genuine biomedical effects. Most of the candidate molecules are far from becomes a drug, because of their pharmacokinetic and pharmacodynamic properties. The introduction of bioisostere to improve properties of molecules and to obtain new class of compound is currently increased. Silicon substitution of carbon of existing drugs is an attractive strategy to search a new candidate with improved biological and physicochemical properties. The fundamental differences between carbon and silicon can lead to improved profile of the silicon containing candidate, and could be exploited to get further benefit in drug design process.
\end{abstract}

Key words: Silicon, Silanols, Silanediols, Silanetriols, Isostere

\section{Introduction}

In the last decade, silicon containing organic inhibitors is gaining popularity in the drug design process. Silicon has atomic number 14 and mass 28.0855. Fig. 1 represents the general structures of organosilicon, silanol, silanediol and silanetriol. Recently, it has been shown that the organosilicon containing inhibitors has wide range of application against disease targets ${ }^{[1]}$. Silicon has four valancy and belongs to IV group in periodic table. Four valancy of silicon leads to control the substitution pattern, steric hindrance, hydrophobicity, solubility and pharmacokinetic property of the developed inhibitors. Silicon substitution of carbon in existing drug is attractive strategy to search for new drug like candidate with favorable biological properties. In the literature there have been number of silicon containing inhibitors are reported with the different synthesis strategy against different targets ${ }^{[2-5]}$. Silicon containing organic molecules such as silanols, silandiols, and silyl fluoride are particularly interesting to chemists, because of their different biochemical properties compared to their carbon

${ }^{1}$ Department of Pharmacoinformatics, NIPER, Sector-67, SAS Nagar, Mohali, Punjab 160062, INDIA

${ }^{2}$ Department of Bio-New Drug Development, College of Medicine, Chosun University, Gwangju 501-759, Korea

${ }^{3}$ Department of Cellular $\cdot$ Molecular Medicine, College of Medicine, Chosun University, Gwangju 501-759, Korea

†Corresponding author : gadhe.changdev@gmail.com, chosj@chosun.ac.kr (Received: December 4, 2012, Revised : December 15, 2012, Accepted : December 21, 2012) containing isosteres. Ideal methodology to optimize the potency and reduce toxicity is isosteric replacement of carbon by silicon. Introduction of silicon into the organic molecule governs change in physical and chemical properties of the molecules which are as follows.

- Higher bond length of C-Si bond (1.87 $\AA$ ) compared to $\mathrm{C}-\mathrm{C}$ bond $(1.54 \AA)$

- Different bond angle and ring structure where silicon atom is introduced

- Increase in lipophilicity of silicon containing compound compare to carbon containing compound, which can enhance tissue permeability

- Electropositive nature of silicon atom enhance hydrogen bond forming capability of silanols

- Silicon containing organic molecules are devoid of any known toxicity

Change in bond length lead to subtle differences in shape and size of silicon containing compound compared to the carbon containing compound. This may result in different interaction pattern of silicon and carbon containing compound with protein/enzyme. However, silicon is more electropositive and has different bond polarization compared to the carbon. Hydrogen bond donor capability of the silanol is more favorable than that of the carbinol. Silicon containing compounds are more lipophilic than their carbon counterpart. A small increase in lipophilicity can lead to increase in volume of distribution of molecule, reflecting enhanced penetration. As outcome, the molecule will be less 
<smiles>[R][Si]([R])([R])[2H]</smiles><smiles>[R][Si]([R])([R])O</smiles><smiles>[R][Si]([R])(O)O</smiles><smiles>[R][Si](O)(O)O</smiles>

Organosilicon Silanol

Silanediol Silanetriol

Fig. 1. Chemical representations of the general oragnosilicon, silanol, silanediol, and silanetriol.

prone to liver metabolism and will have higher plasma half life time. Moreover, silicon containing compounds offer an advantage to identify candidate molecule with different mode of action. The silicon containing organic compounds are very less in number, and not much attention has been paid to it. But, recently number of studies has been performed on silicon containing bioisostere synthesis. Silicon containing organic inhibitor could be exploited for their mode of action against different drug targets using docking, charge calculation and molecular dynamic simulation study. Previous report shows that how to calculate and apply charges to a small molecule ${ }^{[6,7]}$. Our group previously reported the reviews about pseudoreceptor and P-glycoprotein ${ }^{[8,9]}$. However, recent developments about small molecule search space and scoring function in molecular docking has been reported ${ }^{[10-11]}$.

This review focused on the general properties of silicon containing inhibitors as well as use of organic silicon to target different diseases. More detailed discussion about synthetic strategy for silicon containing organic compounds and their bioactivity is elaborated in earlier reviews ${ }^{[12-17]}$.

\section{Stability of Silicon Containing Organic Molecules}

Silicon containing compounds are thermodynamically stable but kinetically liable in acidic and aqueous solutions ${ }^{[18,19]}$. There are reactivity differences between di-alkyl ether (C-OC) and alkoxy silane ether (Si-OC). Based on the substitution pattern on silicon hydrolysis rate can be effectively controlled. $\mathrm{Si}=\mathrm{C}$ bond is unstable under all the condition, but stability and breakdown of the Si-aryl can be effectively controlled by size and electronic nature of aryl ring ${ }^{[9]}$. In some cases adjacent functional group on silicon plays major role in the stability of organosilicon.

\section{Silicon Containing Ether in Drug Delivery}

Silicon containing ethers are a good option to control drug release from the formulations. It has been reported that $\mathrm{O}-$ and $\mathrm{N}$-silicon containing ethers are acid sensitive and explored for their drug release pattern ${ }^{[20]}$. Controlled hydrolysis rate of silicon containing ethers are important for the drug delivery and release for silicon containing nanoparticles ${ }^{[21]}$. However, the prodrug approach was used by DeSimone et al to release drug from biocompatible nanoparticles ${ }^{[22]}$. The rate of drug release can be altered by changing size of the alkyl substitution of silicon containing ethers.

\section{Silicon Isosteres in Inhibitors}

Silicon containing compounds have been recently synthesized as carbon isostere and evaluated for their biological activities. It has been reported that the $\mathrm{t}-\mathrm{Bu}$ group of the p38 MAPK inhibitors (BIRB-796) was replaced by trimethylsilyl and this compound is as equipotent as BIRB-796 ${ }^{[2]}$. Fig. 2 represents BIRB-796 and SiBIRB-796. It has been also reported that the silicon containing BIRB-796 is less affected to degradation by liver microsomes. Isosteric replacement by silicon is

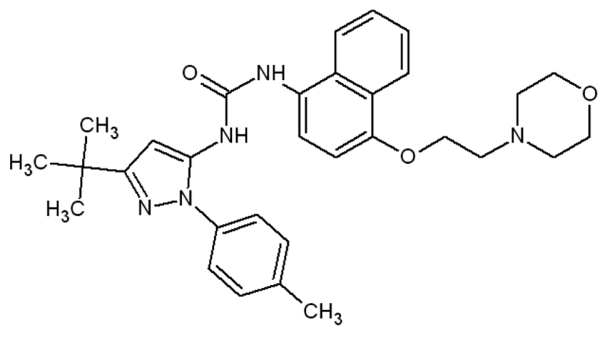

BIRB-796<smiles>Cc1ccc(-n2nc(S(C)(C)C)cc2NC(=O)Nc2ccc(OCCN3CCOCC3)c3ccccc23)cc1</smiles>

SiBIRB-796

Fig. 2. p38 MAPK inhibitor BIRB-796 and its silicon derivatives (SiBIRB-796) ${ }^{[2]}$. 
<smiles>COc1ccc(C(CN(C)C)C2(O)CCCCC2)cc1</smiles>

Fig. 3. Venlafaxine and sila-venlafaxine

successfully used in nuclear receptor, vanilloid receptor $(\mathrm{VR} 1)^{[23-25]}$.

\section{Hydroxy and Dihydroxy and Trihydroxy Analogue of Silicon}

Hydrogen bonding capability and acidity of silicon containing inhibitors can be modified based on the presence of number of hydroxyl groups ${ }^{[15,26,27]}$. Sila-vanlafexine is a silanols and found to have different conformation of ring when silicon is introduced in it compared to the carbon in ring (Fig. 3) ${ }^{[18]}$. As a pioneered work on silanediol, Sieburth reported the first crystal structure for thermolysin inhibitor bound in active site ${ }^{[15]}$. Trialkylsilanols are reported to increase antimicrobial activity against $E$. coli, $S$. aureus, P. aeruginosa compare to their carbon isostere ${ }^{[28]}$. The improved antimicrobial activity is result of improved acidity and correct balance between the hydrophiliclipophilic regions.

\section{Limitations}

Silicon does not form double bond containing compound like common carbon $(\mathrm{C}=\mathrm{C}, \mathrm{C}=\mathrm{O})$ system. However, it cannot form physiologically stable $\mathrm{Si}-\mathrm{H}$, because the bond itself is weaker than the $\mathrm{C}-\mathrm{H}$ bond and has reverse polarity $\left[\mathrm{Si}(\delta+)-\mathrm{H}\left(\delta^{-}\right)\right.$versus $\left.\mathrm{C}(\delta-)-\mathrm{H}\left(\delta^{+}\right)\right]$. Hence, $\mathrm{Si}-\mathrm{H}$ bond behaves differently than $\mathrm{C}-\mathrm{H}$ and easily cleaved by water under non acidic condition forming corresponding silanol (Si-OH).

\section{Conclusion}

This short review highlighted the current prospect of silicon in drug discovery process. Flexible properties of organosilicons such as hydrogen bonding capability, hydrophobicity, acidity and no associated toxicity made its impact in inhibitor design and synthesis for the number of drug targets (antimicrobial, anticancer and antiviral). Poorly permeable drug can be modified for the increase in cell penetration by incorporating silicon isostere. Moreover, release of drug can be controlled using silicon prodrug. The diverse properties of silicon will be used in near future to solve the number of problems associated in drug discovery. Though, the organosilicons are making its impact in drug discovery process, but it has long way to go.

\section{Acknowledgments}

This research was supported by Basic Science Research Program through the National Research Foundation of Korea (NRF) funded by the Ministry of Education, Science and Technology (2012001465)

\section{References}

[1] A. K. Franz and S. O. Wilson, "Organosilicon Molecules with Medicinal Applications", J. Med. Chem., DOI: 10.1021/jm3010114, 2012.

[2] M. J. Barnes, R. Conroy, D. J. Miller, J. S. Mills, J. G. Montana, P. K. Pooni, G. A. Showell, L. M. Walsh, and J. B. H. Warneck, "Trimethylsilylpyrazoles as novel inhibitors of p38 MAP kinase: A new use of silicon bioisosteres in medicinal chemistry", Bioorg. Med. Chem. Lett., Vol. 17, pp. 354-357, 2007.

[3] S. McN. Sieburth, T. Nittoli, A. M. Mutahi, and L. Guo, "Silanediols: A new class of potent protease inhibitors", Angew. Chem. Int. Ed., Vol. 37, pp. 812-814, 1998.

[4] R. Tacke, V. I. Handmann, R. Bertermann, C. Burschka, M. Penka, and C. Seyfried, "Silaanalogues of high-affinity, selective $\sigma$ ligands of the spiro[indane1,4'-piperidine] type: Syntheses, structures, and pharmacological properties", Organometallics, Vol. 22, pp. 916-924, 2003.

[5] R. Tacke, T. Heinrich, R. Bertermann, C. Burschka, A. Hamacher, and M. U. Kassack, "Sila-haloperidol: A silicon analogue of the dopamine (D2) receptor antagonist haloperidol", Organometallics, Vol. 23, pp. 4468-4477, 2004.

[6] S. J. Cho, "Calculation and application of partial charges”, J. Chosun Natural Sci., Vol. 3, pp. 226$230,2010$. 
[7] S. J. Cho, "Meaning and definition of partial charges", J. Chosun Natural Sci., Vol. 3, pp. 231236, 2010.

[8] G. Kothandan, T. Madhavan , C. G. Gadhe, and S. J. Cho, "Pseudoreceptor: concept and overview", J. Chosun Natural Sci., Vol. 3, pp. 162-167, 2010.

[9] C. G. Gadhe and S. J. Cho, "Modulation of multidrug resistance in cancer by p-glycoprotein", J. Chosun Natural Sci., Vol. 4, pp. 23-30, 2011.

[10] S. J. Cho, "Search space reduction techniques in small molecular docking", J. Chosun Natural Sci., Vol. 3, pp. 143-147, 2010.

[11] H. W. Chung and S. J. Cho, "Recent development of scoring functions on small molecular docking", J. Chosun Natural Sci., Vol. 3, pp. 49-53, 2010.

[12] G. A. Showell and J. S. Mills, "Chemistry challenges in lead optimization: Silicon isosteres in drug discovery", Drug Discov. Today, Vol. 8, pp. 551556, 2003.

[13] P. K. Pooni and G. A. Showell, "Silicon switches of marketed drugs", Mini-Rev. Med. Chem., Vol. 6, pp. 1169-1177, 2006.

[14] A. K. Franz, "The synthesis of biologically active organosilicon small molecules", Curr. Opin. Drug Discovery Dev., Vol. 10, pp. 654-671, 2007.

[15] S. McN. Sieburth and C.-A. Chen, "Silanediol protease inhibitors: From conception to validation", Eur. J. Org. Chem., Vol. 2006, pp. 311-322, 2006.

[16] S. Gately and R. West, "Novel therapeutics with enhanced biological activity generated by the strategic introduction of silicon isosteres into known drug scaffolds", Drug Dev. Res., Vol. 68, pp. 156163, 2007.

[17] W. Bains and R. Tacke, "Silicon chemistry as a novel source of chemical diversity in drug design", Curr. Opin. Drug Discovery Dev., Vol. 6, pp. 526543, 2003.

[18] F. D. Osterholtz and E. R. Pohl, "Kinetics of the hydrolysis and condensation of organofunctional alkoxysilanes: A review", J. Adhes. Sci. Technol., Vol. 6, pp. 127-149, 1992.

[19] J. S. Mills and G. A. Showell, "Exploitation of silicon medicinal chemistry in drug discovery", Expert Opin. Invest. Drugs, Vol. 13, pp. 1149-1157, 2004.

[20] F. T. Chiu, Y. H. Chang, G. Ozkan, G. Zon, K. C. Fichter, and L. R. Phillips, "Synthesis, hydrolytic reactivity, and anticancer evaluation of $\mathrm{N}$ - and $\mathrm{O}$-triorganosilylated compounds as new types of poten- tial prodrugs", J. Pharm. Sci., Vol. 71, pp. 542-551, 1982.

[21] T. Johansson, L. Weidolf, F. Popp, R. Tacke, and U. Jurva, "In vitro metabolism of haloperidol and silahaloperidol: New metabolic pathways resulting from carbon/silicon exchange", Drug Metab. Dispos., Vol. 38, pp. 73-83, 2010.

[22] M. C. Parrott, M. Finniss, J. C. Luft, A. Pandya, A. Gullapalli, M. E. Napier, and J. M. DeSimone, "Incorporation and controlled release of silyl ether prodrugs from PRINT nanoparticles", J. Am. Chem. Soc., Vol. 134, pp. 7978-7982, 2012.

[23] J. O. Daiss, C. Burschka, J. S. Mills, J. G. Montana, G. A. Showell, I. Fleming, C. Gaudon, D. Ivanova, H. Gronemeyer, and R. Tacke, "Synthesis, crystal structure analysis, and pharmacological characterization of disila-bexarotene, a disila-analogue of the RXR-selective retinoid agonist bexarotene", Organometallics, Vol. 24, pp. 3192-3199, 2005.

[24] J. O. Daiss, C. Burschka, J. S. Mills, J. G. Montana, G. A. Showell, J. B. H. Warneck, and R. Tacke, "Sila-venlafaxine, a sila-analogue of the serotonin/ noradrenaline reuptake inhibitor venlafaxine: Synthesis, crystal structure analysis, and pharmacological characterization", Organometallics, Vol. 25, pp. 1188-1198, 2006.

[25] M. Chang, S.-R. Park, J. Kim, M. Jang, J. H. Park, J. E. Park, H.-G. Park, Y.-G. Suh, Y. S. Jeong, Y.H. Park, and H.-D. Kim, "Silicon switch approach in TRPV1 antagonist MK-056and its analogues", Bioorg. Med. Chem., Vol. 18, pp. 111-116, 2010.

[26] J. O. Daiss, C. Burschka, J. S. Mills, J. G. Montana, G. A. Showell, J. B. H. Warneck, and R. Tacke, "Sila-venlafaxine, a sila-analogue of the serotonin/ noradrenaline reuptake inhibitor venlafaxine: Synthesis, crystal structure analysis, and pharmacological characterization", Organometallics, Vol. 25, pp. 1188-1198, 2006.

[27] M. Blunder, N. Hurkes, S. Spirk, M. List, and Pietschnig, R. "Silanetriols as in vitro inhibitors for AChE", Bioorg. Med. Chem. Lett., Vol. 21, pp. 363365, 2011

[28] Y.-M. Kim, S. Farrah, and R. H. Baney, "Structureantimicrobial activity relationship for silanols, a new class of disinfectants, compared with alcohols and phenols", Int. J. Antimicrob. Agents, Vol. 29, pp. 217-222, 2007. 